\title{
Significant decrease of hydride decomposition enthalpy in ordered Mg-In alloys induced by growing hydrogen concentration
}

\author{
J. Cermak ${ }^{1,2 *}$, L. Kral $^{1}$, P. Roupcova ${ }^{1,3}$ \\ ${ }^{1}$ Institute of Physics of Materials AS CR, v.v.i., Zizkova 22, CZ-61662 Brno, Czech Republic \\ ${ }^{2}$ CEITEC-Institute of Physics of Materials, AS CR, v.v.i., Zizkova 22, CZ-61662 Brno, Czech Republic \\ ${ }^{3}$ CEITEC-Brno University of Technology, Purkynova 123, CZ-61200 Brno, Czech Republic
}

Received 9 January 2020, received in revised form 4 February 2020, accepted 5 February 2020

\begin{abstract}
Hydrogen sorption in four ball-milled $\mathrm{Mg}-x \operatorname{In}$ alloys (with $x=9,61,69$, and 81 wt.\%) was studied. It was found that pressure-concentration isotherms (PCI curves) of hydrogen desorption from disordered alloy (9 wt.\% In) showed "ordinary" appearance leading to a constant hydride decomposition enthalpy $\Delta H$ close to the value known for pure $\mathrm{Mg}$; however, the plateaus of PCI's obtained for desorption from ordered alloys ( $x>9$ wt.\% In) were significantly upward-curved. Observed values of $\Delta H$ in ordered alloys were lower and decreased with increasing $x$ and hydrogen concentration. Results were explained by size effect.
\end{abstract}

K e y w o r d s: hydrogen storage, Mg alloys, ordering, hydrides, ball milling

\section{Introduction}

Extensive research is steadily devoted to searching effective ways on how to store energy [1-3]. According to the current commonly accepted opinion, hydrogen might serve as a fuel that can be used to storing and re-generating "green" energy from a secondary source [4]. Hence, hydrogen storage (HS) became an issue of primary importance in the sense of storage and transport of conserved energy [ $5-7]$. HS in solid-state avoids safety hazards - nowadays commonly tolerated - coupled with usage of containers with compressed or liquefied hydrogen. Astonishingly, both volumetric and gravimetric density of hydrogen stored in solid-state may be higher than that stored in compressed and even that in the liquefied form [8].

Many diverse materials for HS were investigated up to now $[9,10]$, but the magnesium hydride $\mathrm{MgH}_{2}$ remains one of the most prospective ones [11-21] due to relatively high storage capacity, favorable production costs, abundance of $\mathrm{Mg}$ and, last but not least, to bio-neutral reaction and non-toxicity of $\mathrm{Mg}$.

However, the high thermodynamic stability of $\mathrm{MgH}_{2}$ together with sluggish hydrogen sorption kinetics in $\mathrm{Mg}$ blocks the application of $\mathrm{Mg}$ at lower tem- peratures. There are four main strategies effectual in improving sorption kinetics: alloying [11], nano-sizing [22], nano-confinement [11] and catalysis [9-11, 23]. Moderate success was achieved as for lowering in thermodynamic stability of $\mathrm{Mg}$-based hydride phase up to now [10]. Improvement in $\mathrm{MgH}_{2}$ destabilization was reported in disordered solid solutions Mg-In [24-26].

Using Mg-based alloys with a tendency to longperiod stacking order (LPSO) [27] may be a new way how to decrease the thermodynamic stability of $\mathrm{MgH}_{2}$ and, at the same time, to preserve other favorable features of Mg-based HS alloys. It was reported that LPSO in complex HS alloys led to nucleation of phases formed during hydrogenation that acted as a very fine distributed catalyst for hydrogen storage [27-32]. Therefore, it is highly eligible to orient future research in this direction.

LPSO structure is, in fact, a derivative of hexagonal close-packed structure that can be generated by stacking of hexagonal basal planes 0001 in a sequence ...ABABAB.... Introduction of a plane $\mathrm{C}$ produces a stacking fault (SF) that can be understood as local FCC interlayer (regular FCC structure originates by stacking 111 planes in a sequence ...ABCABC...) [33]. LPSO structures have been investigated in past two

*Corresponding author: e-mail address: cermak@ipm.cz 
decades first of all as structural (not functional) materials owing to their low density, high specific strength and specific stiffness and good cast characteristics, which have a high potential to be used in automotive and aerospace industries [34].

Based on recently published results, utilization of LPSO phases seem to be also a novel way, how to improve HS performance. New Mg-based hydrogen storage materials (HSMs) with LPSO were investigated, e.g., in [23, 27-32, 34-36]. Their interaction with hydrogen was studied, e.g., in [22, 29, 30, 32, 37, 38]. Possible facilitation of HS in LPSO structures was reported, e. g., in $[30,31,37]$, where the authors showed that complex several-stage sorption reactions running in HSM with LPSO could decrease overall energy budget of the sorption process as a whole. The beneficial effect of LPSO is not straightforward. It was found that the ordered structure was not restored after the first hydrogenation cycle [23, 27-32, 34-36]. Instead, the additive elements segregate to SF's, generate (more or less) stable structures [27] that are approximately regularly distributed [27, 39, 40]. They generate nucleation loci that grow to very finely dispersed particles [31]. These particles act as extraordinary effective intrinsic catalysts for the hydrogenation process. In this sense, LPSO materials, generally, may serve as precursors for HSMs with fine dispersion of effective catalyst, promising for HS applications. Moreover, the fine particles of new phases are located (and persist) in planes along the original SF's that are known to be the paths of rapid hydrogen diffusion. Hence, it can be presumed that these "2D channels" keep their high hydrogen diffusivity due to lattice distortion. This is a further argument that contributes to the attraction of the study of HS in materials prepared from LPSO precursors.

\section{Experimental}

In the present work, we have chosen - as a model material - binary alloy system $\mathrm{Mg}$-In that, in a concentration range between about 25 and 60 at.\% In, forms ordered phases $\beta_{1}, \beta_{2}, \beta^{\prime}$, and $\beta^{\prime \prime}$ [41]: Crys- talline $\mathrm{Mg}_{3} \operatorname{In}\left(\beta_{1}\right)$ phase changes with increasing temperature from $12 \mathrm{R}$ to $3 \mathrm{R}$ phase $\beta^{\prime}$ with $\mathrm{FCC}$ interlayers identical with $\mathrm{L}_{2}$ - prototype $\mathrm{AuCu}_{3}$ and at higher temperature finally to disordered $\beta . \mathrm{Mg}_{2} \operatorname{In}\left(\beta_{2}\right)$ is stable up to about $548 \mathrm{~K}$, and $\mathrm{Mg}_{5} \operatorname{In}_{2}\left(\beta_{3}\right)$ decomposes into ordered $\beta^{\prime}$ and $\beta_{2}$ above $483 \mathrm{~K}$. LPSO phase MgIn $\left(\beta^{\prime \prime}\right)$ has FCC interlayers identical with $\mathrm{L}_{0}$ (prototype $\mathrm{CuAu}$ ) $[42,43]$.

Samples of four alloys were made from pure components $\mathrm{Mg}$ (3N8 purity) and In (4N) by ball milling (BM) technique in hydrogen atmosphere using Fritsch Pulverisette 6 ball-mill. The BM was facilitated by an admixture of about $10 \mathrm{wt} . \%$ carbon black (CB $-2 \mathrm{~N}$ purity). Carbon did not enter any phase, and hence, the studied alloys could be effectively treated as binary alloy systems. Its presence, however, may catalyze the hydrogen sorption kinetics.

The mass ratio of the milling balls to the milled blend was about 60 and the milling cycle - $10 \mathrm{~min}$ milling/50 min cooling - was repeated 90 times. Hydrogen was absorbed under hydrogen gas pressure of $p=2.5 \mathrm{MPa}$, and desorbed into a fixed volume under hydrogen pressure, being always well below the equilibrium hydrogen pressure $p_{\text {eq }}(T)$. The sorption experiments were carried out using Sieverts-type gas sorption analyzer PCT-Pro Setaram Instrumentation at temperatures between 475 and $648 \mathrm{~K}$.

Morphology of milled samples, average chemical composition and chemical maps were observed by SEM TESCAN LYRA3 equipped with X-max80 EDS in the area approximately $300 \mu \mathrm{m} \times 500 \mu \mathrm{m}$ containing about $10^{2}$ grains. The typical grain size was about $30 \mu \mathrm{m}$. Accuracy of the average concentration of substitution elements was within 1.5 wt.\%.

All manipulations of the milled blend inclusive the filling the cuvette were done in the glove box in a protective Ar atmosphere. Sample in the cuvette was transported in a small container filled by Ar and inserted into the sorption apparatus.

\section{Results and discussion}

Nominal chemical composition of ball-milled

Table 1. Experimental alloys. $c_{\text {In }}$ - chemical composition and equilibrium phase composition within the interval of sorption temperatures $\Delta T$ according to literature sources [42-44]

\begin{tabular}{|c|c|c|c|c|c|}
\hline \multirow{2}{*}{ Alloy } & \multirow{2}{*}{$c_{\text {In }}(\mathrm{wt} . \%)$} & \multirow{2}{*}{$\Delta T(\mathrm{~K})$} & \multicolumn{3}{|c|}{ Phase composition } \\
\hline & & & {$[42]$} & {$[44]$} & {$[43]^{*}$} \\
\hline 1 & Mg-9In & $573-648$ & $(\mathrm{Mg})$ & $(\mathrm{Mg})$ & $(\mathrm{Mg})$ \\
\hline 2 & $\mathrm{Mg}-61 \mathrm{In}$ & $523-598$ & $\beta_{1}$ & $\beta^{\prime}$ & $\beta_{1}$ \\
\hline 3 & Mg-69In & $473-598$ & $\beta^{\prime * *},\left(\beta^{\prime}+\beta_{2}\right)^{* * *}$ & $\beta^{\prime}$ & $\beta^{\prime * *},\left(\beta^{\prime}+\beta_{2}\right)^{* * *}$ \\
\hline 4 & Mg-81In & $473-523$ & - & $\beta^{\prime \prime}$ & - \\
\hline
\end{tabular}

* taken from [41], ${ }^{* *} T \geq 573 \mathrm{~K},{ }^{* * *} T<573 \mathrm{~K}$ 
Ta b le 2. Phase composition at room temperature. Literature data are only estimated (there are no exact data on phase boundaries at low temperatures); this work - phase composition obtained by XRD

\begin{tabular}{|c|c|c|c|c|}
\hline \multirow{2}{*}{ Alloy } & \multicolumn{4}{|c|}{ Phase composition } \\
\hline & {$[42]$} & {$[44]$} & {$[43]$} & This work \\
\hline 1 & $(\mathrm{Mg})^{*}$ & $(\mathrm{Mg})^{*}$ & $(\mathrm{Mg})^{*}$ & $(\mathrm{Mg})^{*}$ \\
\hline 2 & $\beta_{1}$ & $(\mathrm{Mg})+\beta^{\prime}$ & $\beta_{1}$ & $\beta_{1}$ \\
\hline 3 & $\beta_{3}+\beta_{2}\left(+\beta^{\prime \prime}\right)$ & $\beta^{\prime}+\beta^{\prime \prime}$ & $\beta_{3}+\beta_{2}\left(+\beta^{\prime \prime}\right)$ & $\beta^{\prime \prime}$ \\
\hline 4 & - & - & - & $\beta^{\prime \prime}+(\operatorname{In})^{* *}$ \\
\hline
\end{tabular}

${ }^{*}$ solid solution of $\mathrm{In}$ in $\mathrm{Mg},{ }^{* *} \beta^{\prime \prime}+$ solid solution of $\mathrm{Mg}$ in $\mathrm{In}$ at $T<473 \mathrm{~K}$ (amorphous at $T \geq 473 \mathrm{~K}$ )
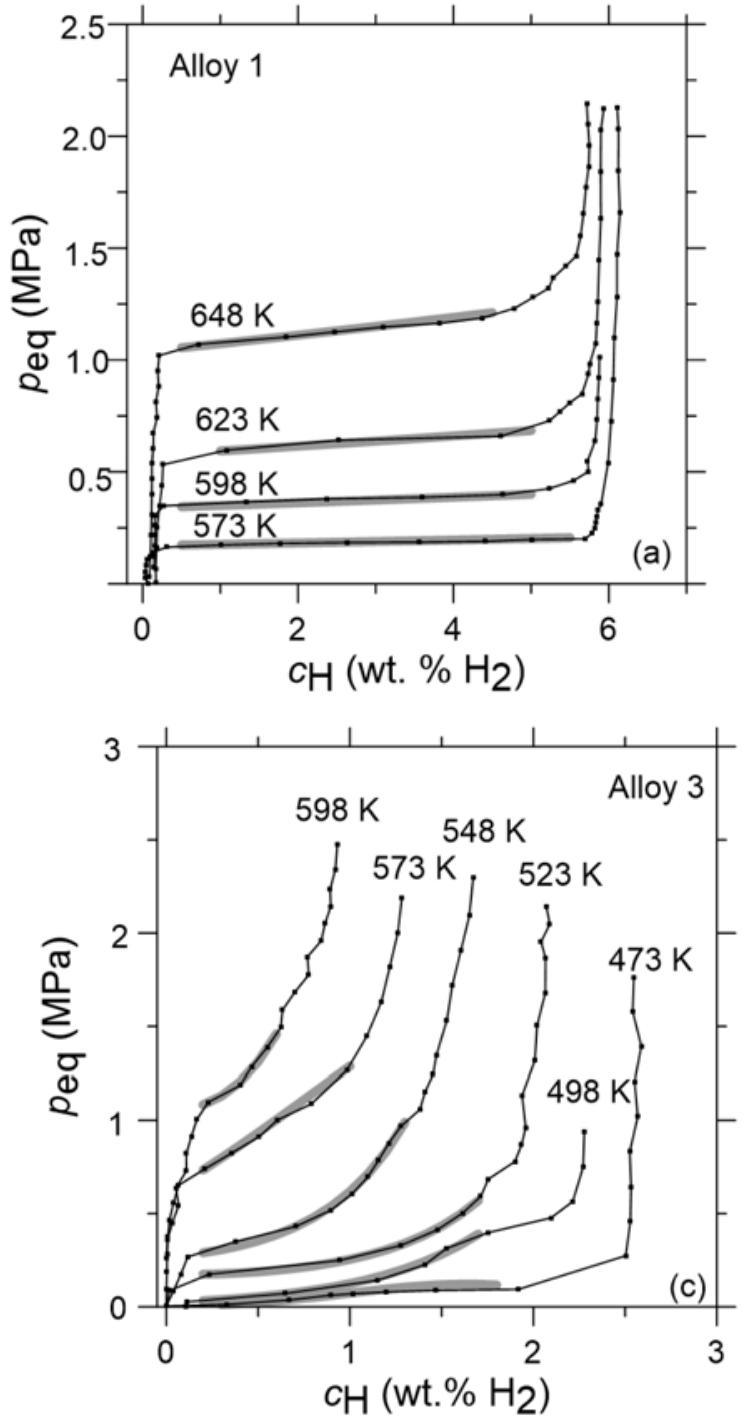
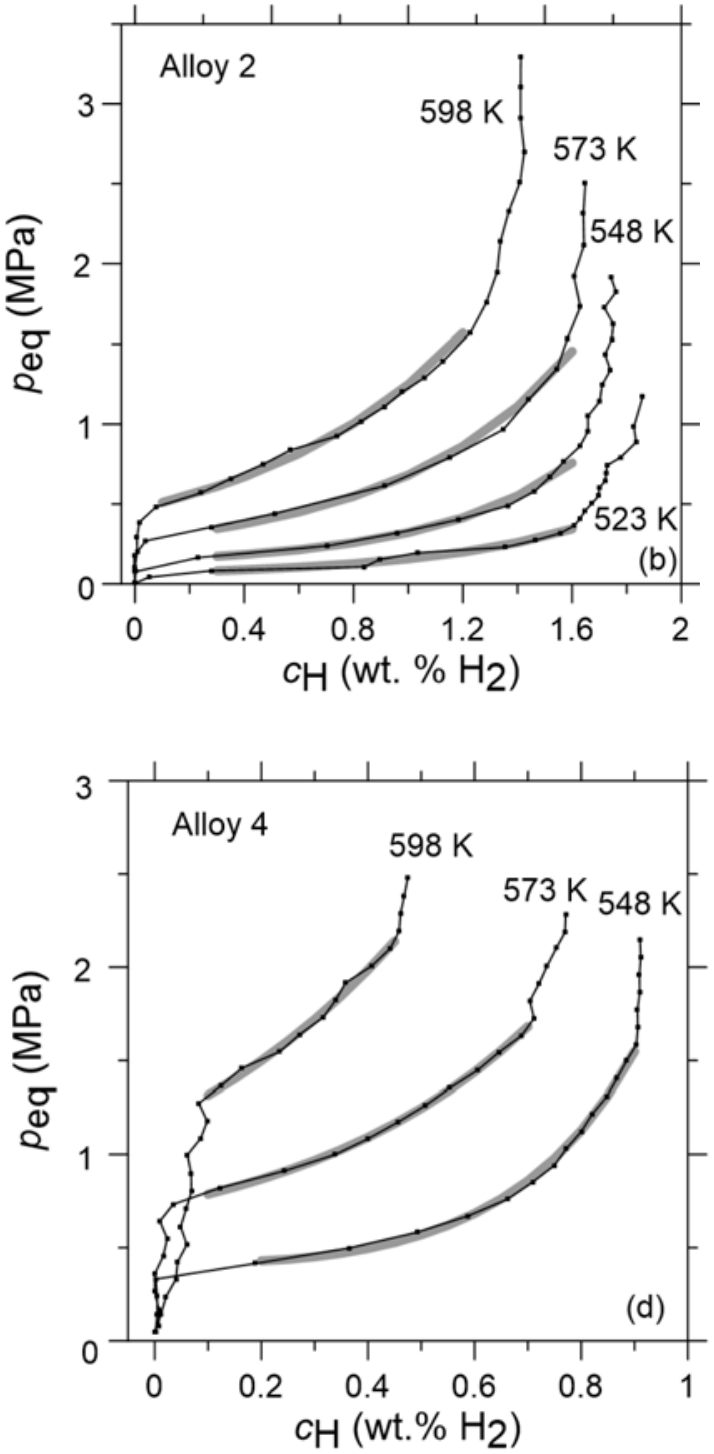

Figs. 1a-d. PCT desorption curves.

batches (irrespective to $\mathrm{CB}$ ) and nominal phase composition of equilibrated alloys according to [42-44] are listed in Table 1.

Alloy 1 represented the HS behavior of the disordered solid solution of In in Mg, Alloy 2 was designed to represent LPSO $\beta_{1}$ structure 12R/3R [42] and Alloys 3 and 4 should behave as ordered structures $\beta^{\prime}$ and $\beta^{\prime \prime}$, respectively.

However, it is difficult to reach an equilibrium state of ordered alloys [41-44]. The structure of both Al- 
loys 3 and 4 was found to be $\beta^{\prime \prime}$ at room temperature even after several hydrogen absorption $(A)$ /desorption $(D)$ cycles - compare present results obtained by XRD with estimations from [42-44] in Table 2.

Pressure-composition isotherms (PCT) of desorption are shown in Fig. 1. It can be seen that PCT curves measured with Alloy 1 (disordered solid solution of $\mathrm{In}$ in $\mathrm{Mg}$ ) show distinctly separated segments. At a small concentration of hydrogen, $c_{\mathrm{H}}$, the first, steep segment is related to the hydrogen solution in a disordered solid solution of hydrogen in $\mathrm{Mg}$. The second part is a slightly sloped, approximately linear plateau, related to a mixture of $\mathrm{Mg}$ with solved hydrogen and hydride phase and the last, steep part, originating in the solution of hydrogen in hydride phase. The subdivision of PCT curves obtained with other alloys into the three segments is much less distinct. Moreover, the medium part of PCT isotherms is considerably convex-curved. In the case of Alloy 4, only two isotherms were measured due to low critical temperature limiting the existence of hydride phase (the maximum temperature at which the hydride phase can exist) $[9]$.

To obtain enthalpy of hydride decomposition, $\Delta H$, from the Vant' Hoff diagram, the value of equilibrium hydrogen pressure, $p_{\text {eq }}$, at the middle of the plateau $([9,10])$ is commonly taken.

Systematic expressive curvature of all PCT's measured with all ordered alloys makes the construction of the Vant' Hoff diagram for Alloys 2-4 in this way difficult. Therefore, respecting the observed curvature, the middle part of all PCT's was fitted by polynomials of second order in $c_{\mathrm{H}}$ (thick gray curves in Fig. 1) and enthalpies $\Delta H$ were calculated using the fitted values of $p_{\mathrm{H}}\left(c_{\mathrm{H}}\right)$ at several values of $c_{\mathrm{H}}$.

It is evident from Fig. 2 that $\Delta H$ does not depend markedly on $c_{\mathrm{H}}$ in disordered Alloy 1 , and that it is close to the value $\Delta H=75 \mathrm{~kJ} \mathrm{~mol}^{-1} \mathrm{H}_{2}$ known for pure Mg [10]. In Alloys $2-4$, however, $\Delta H$ decreases significantly with growing values of $c_{\mathrm{H}}$ and $c_{\mathrm{In}}$. These trends may be a consequence of the size-effect during the hydride decomposition in studied alloys: It can be found that a partial volume of unit cell of $\mathrm{MgH}_{2}$ per one $\mathrm{Mg}$ atom is $61.6 \AA^{3}$ /at $\mathrm{H}$. In Alloy 1 the partial volume of unit cell makes $46.5 \AA^{3} /$ at $\mathrm{Mg}$ [45] and in phases $\beta_{1}, \beta^{\prime \prime}$ and in solid solution (In), the values of volume fraction are $22.6,23.0$, and $26.1 \AA^{3} /$ at $\mathrm{Mg}$, respectively [46]. Hence, it can be concluded that the misfit between the partial volumes falling to one $\mathrm{Mg}$ atom in the original hydride phase on one side and hydrogen-free phase on the other one increases with increasing $c_{\text {In }}$. The size effect can also explain upward curvature of plateaus of PCT curves.

Similar curvature of PCT diagrams was also observed in the case of hydrogen sorption in binary alloy system Mg-Cd [47]. The authors explained the curvature by a decrease of the chemical potential (partial

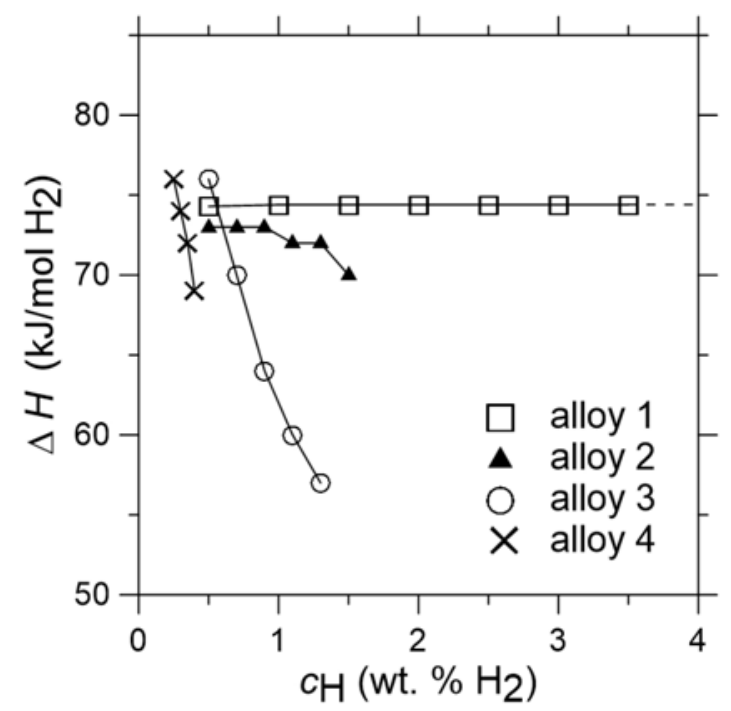

Fig. 2. Hydride decomposition enthalpy $\Delta H$ in dependence on hydrogen concentration $c_{\mathrm{H}}$. Calculated from fitted values obtained from plateaus of desorption PCT isotherms.

molar free enthalpy $\left.\overline{\Delta G_{\mathrm{Mg}}}\right)$ of $\mathrm{Mg}$ in the $\mathrm{Mg}-\mathrm{Cd}$ solid solution with increasing $\mathrm{Cd}$ content in $\mathrm{H}$-free matrix due to the $\mathrm{Cd}$ rejection by the newly formed $\mathrm{MgH}_{2}$. Using thermodynamic model proposed in [47], one can easily obtain (with $\Delta S=0.135 \mathrm{~J} / \mathrm{K} \mathrm{mol}^{-1} \mathrm{H}_{2}$, which is a constant for all HS materials [10]) for $\mathrm{Mg}_{3} \mathrm{Cd}$ values $\Delta H=71.8 \mathrm{~kJ} \mathrm{~mol}^{-1} \mathrm{H}_{2}$ and $61.0 \mathrm{~kJ} \mathrm{~mol}^{-1} \mathrm{H}_{2}$ at $c_{\mathrm{H}}=0 \mathrm{wt} . \% \mathrm{H}_{2}$ and at $c_{\mathrm{H}}=3 \mathrm{wt} . \% \mathrm{H}_{2}$, respectively. It can be speculated that a similar mechanism may be at work also in the Mg-In system.

Another factor that can decrease $\Delta H$ with increasing $c_{\text {In }}$ is easier hydrogen diffusion and mobility in matrix that significantly tends to atomic ordering, since it can be supposed that affinity of one strong hydrideforming element $(\mathrm{Mg})$ of the alloy to hydrogen is lowered by competitive attraction of the element to the other alloy component (In).

Moreover, with increasing $c_{\text {In }}$, the $\mathrm{Mg}$-In alloys show the increasing tendency to a refinement of crystalline grains. Analyzing the width of diffraction peaks in XRD patterns, corresponding to respective majority $\mathrm{Mg}_{x} \operatorname{In}_{y}$ phase, it was found that the size of crystallites, $d$ (more precisely: the size of diffraction area), decreased with increasing $c_{\text {In }}$. In Alloys 2 and 3 , values of $d$ were 478 and $324 \AA$, respectively. Alloy 4 showed even self-amorphizing behavior: When the temperature increased above approximately $T_{\mathrm{a}}=473 \mathrm{~K}$, the crystalline ball-milled matrix $\mathrm{Mg}_{x} \operatorname{In}_{y}$ amorphized, and after the temperature decreased below $T_{\mathrm{a}}$, the peaks of $\mathrm{Mg}_{x} \operatorname{In}_{y}$ phase appeared again - see in Fig. 3. This amorphizig behavior of $\operatorname{Mg}_{x} \operatorname{In}_{y}$ phase was observed repeatedly during temperature cycling. 


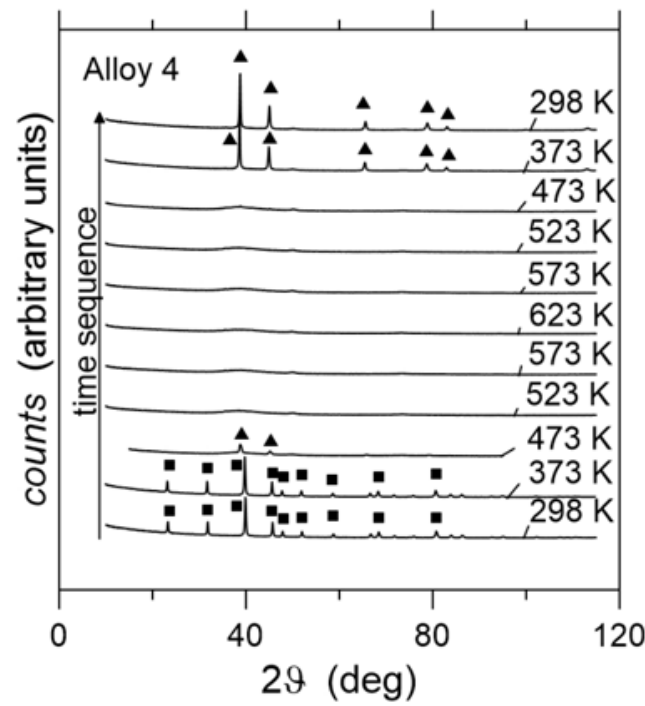

Fig. 3. XRD patterns measured with Alloy 4 at varied temperatures. - MgIn, $-\mathrm{Mg}_{0.1} \operatorname{In}_{0.9}$.

\section{Summary}

It was found in the present paper that Mg-In model alloys that show ordering may serve as prospective precursors for hydrogen storage materials. These materials - due to a high fraction of $\mathrm{Mg}$ - may keep relatively high hydrogen storage capacity of $\mathrm{Mg}$ and, at the same time, the hydride decomposition enthalpy may be lowered compared to common Mg-based crystalline hydrogen storage alloys. This idea is currently being tested with more complex HS materials in running research.

\section{Acknowledgements}

This work was supported by the project of Czech Science Foundation No. 17-21683S and by Central European Institute of Technology, CEITEC-Institute of Physics of Materials, AS CR Brno, Czech Republic.

\section{References}

[1] D. Grosspietsch, M. Saenger, B. Viros, Matching decentralized energy production and local consumption: A review of renewable energy systems with conversion and storage technologies, Wiley interdisciplinary reviews-Energy and environment 8 (2019) e336. doi: $10.1002 /$ wene.336

[2] J. O. Abe, A. P. I. Popoola, E. Ajenifuja, O. M. Popoola, Hydrogen energy, economy and storage: Review and recommendation, Int. J. Hydrogen Energy 44 (2019) 15072-15086. doi:10.1016/j.ijhydene.2019.04.068
[3] J. Kim, S. Sengodan, S. Kim, O. Kwon, Y. Bu, G. Kim, Proton conducting oxides: A review of materials and applications for renewable energy conversion and storage, Renewable \& Sustainable Energy Reviews 109 (2019) 606-618. doi:10.1016/j.rser.2019.04.042

[4] A. Zuettel, A. Borgschulte, L. Schlapbach, Hydrogen as a future energy carrier, Wiley-VCH Verlag GmbH\&Co. KGaA, Weinheim, 2008.

[5] E. Rivard, M. Trudeau, K. Zaghib, Hydrogen storage for mobility: A review, Materials 12 (2019) 1973. doi: $10.3390 / \mathrm{ma1} 121973$

[6] R. Moradi, K. M. Groth, Hydrogen storage and delivery: Review of the state of the art technologies and risk and reliability analysis, Int. J. Hydrogen Energy 44 (2019) 12254-12269. doi:10.1016/j.ijhydene.2019.03.041

[7] J. D. Fonseca, M. Camargo, J. M. Commenge, L. Falk, I. D. Gil, Trends in design of distributed energy systems using hydrogen as energy vector: A systematic literature review, Int. J. Hydrogen Energy 44 (2019) 9486-9504. doi:10.1016/j.ijhydene.2018.09.177

[8] M. Klell, Storage hydrogen in pure form. in: M. Hirscher (Ed.), Handbook of hydrogen storage: New materials for future energy storage, Wiley-VCH Verlag GmbH\&Co. KGaA, Weinheim, 2008, pp. 1-36.

[9] D. Chandra, Intermetallics for hydrogen storage. in: G. Walker (Ed.), Solid-state hydrogen storage/Materials chemistry, Woodhead Publishing Ltd, Cambridge, England, 2008, pp. 315-380.

[10] J. Huot, Metal hydrides. in: M. Hirscher (Ed.), Handbook of hydrogen storage, Wiley-VCH Verlag GmbH\&Co., Weinheim, 2010, pp. 81-116.

[11] Y. Wang, J. Wang, Recent advances in additiveenhanced magnesium hydride for hydrogen storage, Progress in Natural Sci.: Materials Internat. 27 (2017) 41-49. doi:10.1016/j.pnsc.2016.12.016

[12] L. Kral, J. Cermak, Improvement of hydrogen storage properties of $\mathrm{Mg}$ by catalytic effect of Al-containing phases in $\mathrm{Mg}-\mathrm{Al}-\mathrm{Ti}-\mathrm{Zr}-\mathrm{C}$ powders, Int. J. Hydrogen Energy 44 (2019) 13561-13568. doi:10.1016/j.ijhydene.2019.03.188

[13] J. G. Zhang, Y. F. Zhu, L. L. Yao, L. C. Xu, Y. N. Liu, L. Q. Li, State of the art multi-strategy improvement of Mg-based hydrides for hydrogen storage, J. Alloys Compd. 782 (2019) 796-823. doi:10.1016/i.jallcom.2018.12.217

[14] J. Cermák, L. Král, Hydrogen absorption in carbon allotropes and talc, Kovove Mater. 56 (2018) 75-80. doi:10.4149/km_2018_2_75

[15] X. B. Xie, M. Chen, M. M. Hu, B. L. Wang, R. H. Yu, T. Liu, Recent advances in magnesium-based hydrogen storage materials with multiple catalysts, Int. J. Hydrogen Energy 44 (2019) 10694-10712. doi:10.1016/i.ijhydene.2019.02.237

[16] J. Cermák, L. Král, P. Roupcová, Influence of longterm ageing upon the capacity of hydrogen storage in two novel Mg-Ni-In-C alloys, Kovove Mater. 54 (2016) 389-396. doi:10.4149/km_2016_6_389

[17] V. A. Yartys, M. V. Lototskyy, E. Akiba, R. Albert, V. E. Antonov, J. R. Ares, M. Baricco, N. Bourgeois, C. E. Buckley, J. M. Bellosta von Colbe, J.-C. Crivello, F. Cuevas, R. V. Denysa, M. Dornheim, M.Felderhof, D. M. Grant, B. C. Haubacka, T. D. Humphries, I. Jacob, T. R. Jensen, P. E. de Jongh, J.-M. Joubert, M. A. Kuzovnikov, M. Latroche, M. Paskevicius, L. 
Pasquini, L. Popilevsky, V. M. Skripnyuk, E. Rabkin, M. V. Sofianos, A. Stuart, G. Walker, H. Wang, C. J. Webb, M. Zhu, Magnesium based materials for hydrogen based energy storage: Past, present and future, Int. J. Hydrogen Energy 44 (2019) 7809-7859. doi:10.1016/j.ijhydene.2018.12.212

[18] I. Y. Zavalii, V. V. Berezovets', R. V. Denys, Nanocomposites based on magnesium for hydrogen storage: Achievements and prospects (A Survey), Mater. Sci. 54 (2019) 611-626. doi:10.1007/s11003-019-00226-x

[19] Knotek, V., Lhotka, M., Vojtěch, D., Dehydriding behaviour of electrochemically hydrided $\mathrm{Mg}$ Ni-Mm alloys, Kovove Mater. 52 (2014) 345-351. doi:10.4149/km_2014_6_345

[20] Q. Luo, J. D. Li, B. Li, B. Liu, H. Y. Shao, Q. Li, Kinetics in Mg-based hydrogen storage materials: Enhancement and mechanism, J. Magnesium and Alloys 7 (2019) 58-71. doi:10.1016/j.jma.2018.12.001

[21] J. Cermak, L. Kral, I. Stloukal, Hydrogen diffusion in hydrogenated $\mathrm{Mg}$ and $\mathrm{Mg}-\mathrm{Mg} 2 \mathrm{Ni}$ eutectic alloy, Kovove Mater. 45 (2007) 305-312.

[22] L. Pasquini, The effects of nanostructure on the hydrogen sorption properties of magnesium-based metallic compounds: A review, Crystals 8 (2018) 106-134. https://doi:10.3390/cryst8020106

[23] H. Okuda, M. Yamasaki, Y. Kawamura, M. Tabuchi, H. Kimizuka, Nanoclusters first: a hierarchical phase transformation in a novel $\mathrm{Mg}$ alloy, Scientific Reports 5 (2015) 14186. doi:10.1038/srep14186

[24] Ch. Zhou, Z. Z. Fang, J. Lu, X. Zhang, Thermodynamic and kinetic destabilization of magnesium hydride using Mg-In solid solution alloys, J. Amer. Chem. Soc. 135 (2013) 10982-10985. doi:10.1021/ia4058794

[25] Ch. Zhou, Z. Z. Fang, J. Lu, X. Luo, Ch. Ren, P. Fan, Y. Ren, X. Zhang, Thermodynamic destabilization of magnesium hydride using Mg-based solid solution, Alloys J. Phys. Chem. C 118 (2014) 11526-11535. doi:10.1021/jp501306w

[26] H. C. Zhong, H. Wang, J. W. Liu, D. L. Sun, M. Zhu, Altered desorption enthalpy of $\mathrm{MgH}_{2}$ by the reversible formation of $\mathrm{Mg}(\mathrm{In})$ solid solution, Scripta Mater. 65 (2011) 285-287. doi:10.1016/j.scriptamat.2011.04.024

[27] Z.-R. Liu, D.-Y. Li, Stability and formation of long period stacking order structure in Mg-based ternary alloys, Comput. Mater. Sci. 103 (2015) 90-96. doi:10.1016/j.commatsci.2015.03.008

[28] Q. Li, Y. Li, B. Liu, X. Lu, T. Zhang, Q. Gu, The cycling stability of the in situ formed Mg-based nanocomposite catalyzed by $\mathrm{YH}_{2}$, J. Mater. Chemistry A 5 (2017) 17532-17543. doi:10.1039/C7TA04551D

[29] T. Yang, Q. Li, C. Liang, X. Wang, C. Xia, H. Wang, F. Yin, Y Zhang, Microstructure and hydrogen absorption/desorption properties of $\mathrm{Mg}_{24} \mathrm{Y}_{3} \mathrm{M}(\mathrm{M}=\mathrm{Ni}$, Co, Cu, Al) alloys, Int. J. Hydrogen Energy 43 (2018) 8877-8887. doi:10.1016/j.ijhydene.2018.02.199

[30] R. Lapovok, E. Zolotoyabko, A. Berner, V. Skripnyuk, E. Lakin, N. Larianovsky, C. Xu, E. Rabkin, Hydrogenation effect on microstructure and mechanical properties of Mg-Gd-Y-Zn-Zr alloys, Mater. Sci. Eng. A 719 (2018) 171-177. doi:10.1016/j.msea.2018.02.016

[31] J. W. Liu, C. C. Zou, H. Wang, L. Z. Ouyang, M. Zhu, Facilitating de/hydrogenation by long-period stacking ordered structure in Mg based alloys, Int. J. Hydrogen
Energy 38 (2013) 10438-10445. doi:10.1016/j.ijhydene.2013.05.149

[32] Y. Li, Q. Gu, Q. Li, T. Zhang, In-situ synchrotron Xray diffraction investigation on hydrogen-induced decomposition of long period stacking ordered structure in Mg-Ni-Y system, Scripta Mater. 127 (2017) 102107. doi:10.1016/i.scriptamat.2016.09.011

[33] T. B. Massalski, Structure of solid solutions. in: R. W. Cahn, P. Hassen (Eds.), Physical Metallurgy, $3^{\text {rd }}$ edition, North-Holland Phys. Publ., Amsterdam-OxfordNew York-Tokyo, 1983, pp.153-218.

[34] L. U. Fumin, M. A. Aibin, J. Jinghua, Y. Donghui, Z. Qi, Review on long-period stacking-ordered structures in Mg-Zn-RE alloys, Rare Metals 31 (2012) 303-310. doi:10.1007/s12598-012-0510-y

[35] J. Gao, Y. Chen, Y. Wang, Effect of Sn element on the formation of LPSO phase and mechanical properties of Mg-6Y-2Zn alloy, Mater. Sci. Eng. A 711 (2018) 334-342. doi:10.1016/i.msea.2017.11.049

[36] J. Gao, J. Fu, N. Zhang, Y. Chen, Structural features and mechanical properties of $\mathrm{Mg}-\mathrm{Y}-\mathrm{Zn}-\mathrm{Sn}$ alloys with varied LPSO phases, J. Alloys Compd. 768 (2018) 1029-1038. doi:10.1016/i.jallcom.2018.07.227

[37] L. Xie, J. Li, T. Zhang, L. Song, H. Kou, Microstructure and hydrogen storage properties of $\mathrm{Mg}-\mathrm{Ni}-\mathrm{Ce}$ alloys with a long-period stacking ordered phase, J. Power Sources 338 (2017) 91-102. doi:10.1016/j.jpowsour.2016.11.025

[38] K. Ishikawa, T. Kawasaki, Y. Yamada, Hydrogenation behavior of $\mathrm{Mg}_{85} \mathrm{Zn}_{6} \mathrm{Y}_{9}$ crystalline alloy with long period stacking ordered structure, Int. J. Hydrogen Energy 40 (2015) 13014-13021. doi:10.1016/j.ijhydene.2015.07.103

[39] H. Yokobayashi, K. Kishida, H. Inui, M. Yamasaki, Y. Kawamura, Enrichment of $\mathrm{Gd}$ and $\mathrm{Al}$ atoms in the quadruple close packed planes and their in-plane longrange ordering in the long period stacking-ordered phase in the Mg-Al-Gd system, Acta Mater. 59 (2011) 7287-7299. doi:10.1016/j.actamat.2011.08.011

[40] J.-K. Kim, W.-S. Ko, S. Sandloebes, M. Heidelmann, B. Grabowski, D. Raabe, The role of metastable LPSO building block clusters in phase transformations of an Mg-Y-Zn alloy, Acta Mater. 112 (2016) 171-183. doi:10.1016/j.actamat.2016.04.016

[41] T. B. Massalski, Binary alloy phase diagrams - 2nd ed. Plus Up-Dates, ASM Int. ASM/NIST 1996, Materials Park OH 44073, CD ROM.

[42] Y. Watanabe, Constitution of the magnesium-indium system near the composition of $\mathrm{Mg}_{3} \mathrm{In}$ and phase transition of $\beta_{1}$ phase, Acta Metall. 23 (1975) 691-696. doi:10.1016/0001-6160(75)90051-6

[43] S. Curtarolo, A. N. Kolmogorov, F. H. Cocks, High-throughput ab initio analysis of the Bi-In, Bi-Mg, $\mathrm{Bi}-\mathrm{Sb}, \mathrm{In}-\mathrm{Mg}$, In-Sb, and Mg-Sb systems, CalphadComputer Coupling Phase Diagrams Thermochem. 29 (2005) 155-161. doi:10.1016/j.calphad.2005.04.003

[44] P. Feschotte, Le système binaire magnesium-indium, J. Less Common Metals 46 (1976) 51-54. doi:10.1016/0022-5088(76)90178-8

[45] A. Becerra, M. Pekguleryuz, Effects of lithium, indium, and zinc on the lattice parameters of magnesium, J. Mater. Res. 23 (2008) 3379-3386. doi:10.1557/JMR.2008.0414

[46] ICSD (Inorganic crystal structures database) - Database for complete identification inorganic crystal 
structures, FIZ-Leibnitz institute for information infrastructure, Karlsruhe, CD ROM.

https://icsd.products.fiz-karlsruhe.de/
[47] V. M. Skripnyuk, E. Rabkin, $\mathrm{Mg}_{3} \mathrm{Cd}$ : A model alloy for studying the destabilization of magnesium hydride, Int. J. Hydrogen Energy 37 (2012) 10724-10732. doi:10.1016/i.ijhydene.2012.04.065. 